\title{
БРИКС
}

\section{нацелилась на общее \\ развитие будущих сетей связи}

В.Тихвинский, д.э.Н., академик РАЕН главный научный сотрудник ФГУП "НИИР", профессор МТУСИ / vtniir@mail.ru

DOI: 10.22184/2070-8963.2019.83.6.56.58

12 августа 2019 года в столице Бразилии состоялось первое заседание совета вновь созданного Института будущих сетей связи БРИКС.

В период с 12 по 14 августа 2019 года в г. Бразилиа (Федеративная Республика Бразилия), состоялось пятое собрание министров связи стран БРИКС. В ходе мероприятия, помимо собственно встречи руководства администраций связи, прошли четвертое заседание Рабочей группы БРИКС по ИКТ-кооперации и пятая бизнес-встреча представителей БРИКС, а также первое заседание совета вновь созданной интеграционной структуры - Института будущих сетей связи БРИКС.

Совет BIFN собрался 12 августа в здании Министерства инноваций Бразилии. На его заседании присутствовали делегации всех пяти стран группы БРИКС (более 30 человек), которые обсудили Положение об институте, полномочия, направления исследовательских работ, организационную структуру и механизмы финансирования. Российская делегация, в которую входил автор статьи, внесла ряд важных редакционных изменений в Положение.

По итогам заседания совета с учетом Плана действий по развитию ИКТ БРИКС, который был принят в г. Бангалоре (Индия), в 2016 году были утверждены следующие цели и задачи BIFN:

- обеспечить платформу для совместных исследований, инноваций и обучения специалистов;

- разработать дорожную карту по развитию будущих сетей связи и сотрудничать с глобальными партнерами для совместного решения соответствующих проблем;

- содействовать сотрудничеству в области исследований и инноваций в области новых сетей и новых технологий;

- создать платформу сотрудничества для исследований и разработок и инноваций в будущих сетях между различными учреждениями и организациями в странах БРИКС;

- координировать усилия с органами стандартизации и развития (SDO) стран БРИКС для стандартизации сетей, сетевых элементов и устройств, а также с целью облегчения проведения испытаний новых сетей.

Институт BIFN будет "ориентированным на спрос, управляемым проектом, открытым, платформен ным и научно управляемым". С учетом предложений фокус-группы BIFN основная сфера деятельности организации будет включать следующие виды:

- разработку перспектив исследований с горизонтом планирования 4-7 лет и консультирование по проектам, основанным на результатах совместных исследований, международных тенденциях, а также на предложениях совета института;

- создание проектов сотрудничества, в том числе открытых для национальных исследовательских институтов, академических учреждений, малых и средних предприятий;

- создание профессиональных лабораторий и стендов для испытаний в целях исследований, инноваций и тестирования, а также создание открытых сервисных платформ для тестирования сетевых продуктов;

- обмен экспертами и наращивание потенциала в новых технологических областях;

- развитие работы в области стандартизации, разработку совместных предложений по стандартам в рамках деятельности BIFN и сотрудничество с международными организациями, занимающимися вопросами стандартизации; 
- мониторинг и обновление Рабочей программы BIFN, утвержденной советом института;

- работа над проектами НИОКР по будущим сетям и новым технологиям;

- поощрение исследовательских институтов, стартапов и предприятий для проведения исследований и инноваций путем совместного изучения и публикации официальных документов по технологическому и промышленному развитию будущих сетей и новых ИКТ;

- развитие других областей по согласованию с советом.

На заседании Совета BIFN также была определена организационная структура Института, которая представлена на рис.1, и структура управления будущих сетей БРИКС, состоящая из Совета, филиалов института и секретариата BIFN.

Совет Института является директивным органом BIFN, построенным на консенсусе членов и управляемом ими под председательством ротационного представителя одной из стран-учредителей (председателя), который отчитывается перед министрами связи БРИКС через рабочую группу БРИКС по сотрудничеству в области ИКТ и сообщает о ходе работ Института.

Оперативным органом управления институтом является секретариат, основной задачей которого является оказание поддержки совету

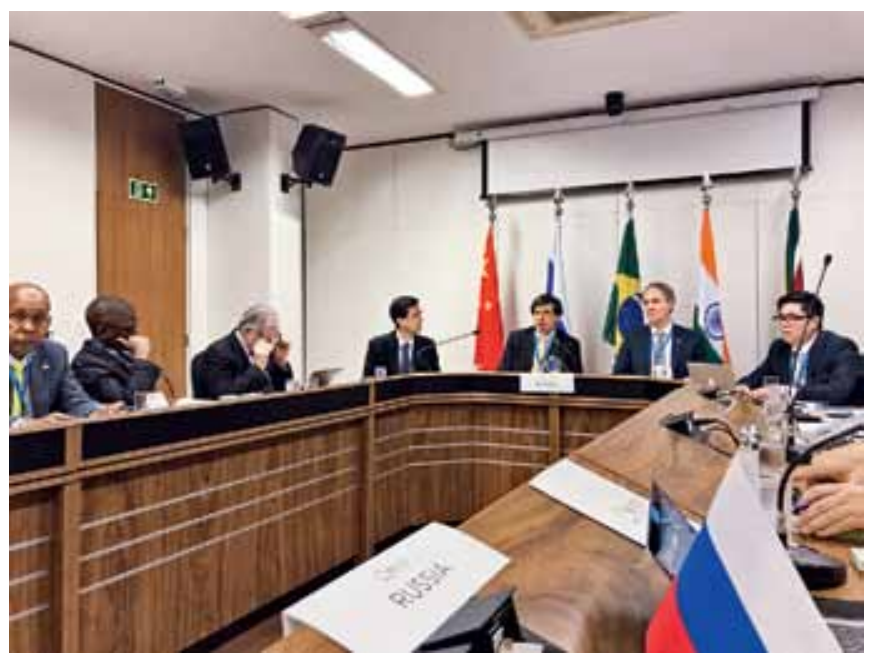

в рамках его мандата. Секретариат BIFN будет, как это было предложено на четвертом собрании министров связи в г. Дурбане в 2018 году, в начальный период - до создания постоянной структуры - предоставляться председательствующей страной БРИКС и может быть поддержан другим членом БРИКС для оказания помощи председателю совета в выполнении текущей работы, в подготовке и организации заседаний совета и рабочих групп, а также координации деятельности BIFN в период между заседаниями совета.

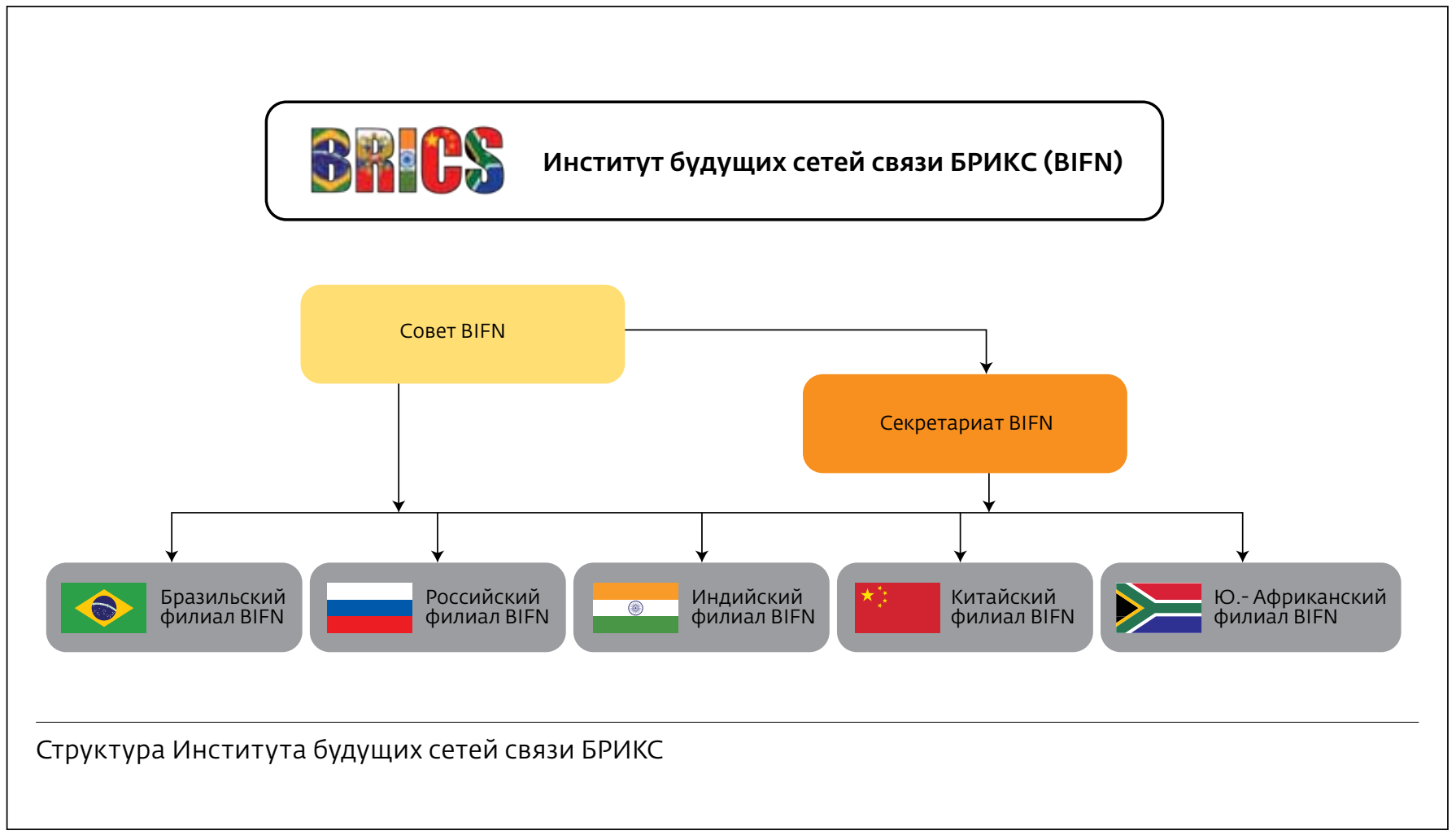


Филиалы BIFN - это национальные институты, создаваемые в странах-учредителях, которые должны активно проводить исследования ключевых сетевых технологий с учетом общего планирования и программ обучения Института.

В обязанности национальных филиалов BIFN включено:

- выступать координационным центром БРИКС для своих национальных институтов и координировать деятельность учреждений, промышленности для участия в исследованиях и мероприятиях BIFN для развития ИKT;

- быть координационным центром для других филиалов BIFN;

- выступать национальным координационным центром для секретариата и совета BIFN;

- информировать о результатах исследований и делать их доступными;
- принимать на себя обязанности секретариата BIFN, когда страна принимает ротационное председательство в БРИКС;

- проводить встречи, связанные с деятельностью BIFN;

- выполнять функции учебной базы Института, предлагая соответствующее обучение членам BIFN;

- принимать участие в учебной работе BIFN;

- содействовать предоставлению высокоскоростной и качественной связи и сетевой инфраструктуры, подключая для этого сети NREN (национальные исследовательские и образовательные сети).

Обеспечение деятельности национальных филиалов Института BIFN, их финансирование и решение кадровых вопросов возлагаются на каждую страну БРИКС соответственно.

\section{Keysight открыла в Москве лабораторию по тестированию устройств 5G}

Компания Keysight Technologies сообщила 29 августа, что развертывает первую в России лабораторию по тестированию сетевых устройств 5 С.

Внедрение пятого поколения стандартов беспроводной сотовой связи ведет к значительным изменениям в телекоммуникационной отрасли. Использование 5C New Radio увеличит скорость передачи данных, уменьшит задержки, повысит надежность и обеспечит более гибкие сетевые конфигурации. Но реализация каждой из этих новых возможностей ставит целый рядпроблем перед разработчиками оборудования и операторами сетей $5 \mathrm{C}$.

В частности, производителям сетевого оборудования необходимо внедрить новые сложные технологии МIMO и формирования диаграммы направленности, интегрировать новую инфраструктуру миллиметрового диапазона, а операторам связи уделять особое внимание соответствию используемых в их сети устройств новым стандартам , про-

\section{водить приемочные испытания оборудования и обе-} спечить масштабирование сетей $5 \mathrm{C}$.

С целью эффективной проверки разрабатываемых и используемых устройств 5С в московском офиce Keysight организована лаборатория с комплексом решений для реализации многочисленных сценариев тестирования абонентского и базового оборудования, ядром которого является специализированный имитатор UXM 5C Е7515B.

Данное решение формирует сигналы базовой станции (БС) и осуществляет протокольный обмен с тестируемым терминалом. В частности, может быть реализована БС любого частотного диапазона в рамках полосы FRI, при этом удаленно доступна и демонстрация аналогичных решений для устройств полосы FR2 в условиях эфирных испытаний ОТА. Тестирование возможно как в режиме развертывания сети Non-standalone, так и Standalone.
На базе новой лаборатории Кeysight операторы и разработчики устройств могут проверять такие сценарии, как процедура первичного доступа к сети; протокольный обмен с базовыми станциями; пропускная способность по ІР-трафику для различных услуг; изменение схемы кодирования "на лету" и обработка специфичных сценариев подключения; проверка в ВЧ-части и протокольные тесты по ЗСРР TS 38.101.

Установленное в лаборатории оборудование также позволяет тестировать качество передатчиков терминалов, контролируя ихспектр, EVM, внеполосные излучения. Проверка приемников доступна за счет оценки чувствительности и гибких возможностей по управлению выходным сигналом эмулятора, в том числе при внесении реалистичных искажений в канал связи.

По информации компании Keysight Technologies

\section{Tele2 отчитался о6 итогах работы сети LTE-450}

Компания Tele2 (000 "T2 Мобайл") подвела итоги работы своей сети LTE-450 под брендом Skylink, "доставшимся" от оператора CDMA-450, по итогам шести месяцев 2019 года. Абонентская база Skylink выросла на 121\%.

В первом полугодии наибольший рост потребления интернет-трафика показали абоненты Санкт-Петербурга и Ленинградской обла- сти - он составил 139\% по сравнению с концом 2018 года. На втором месте - Москва и область с показателем в 135\%. В Твери рост потребления интернета составил 120\%, а в Великом Новгороде - $108 \%$.

Tele2 - единственный сотовый оператор в России, предоставляющий услуги связи в стандарте LTE в диапазоне 450 МГц.
Услуги под брендом Skylink доступны абонентам в Москве и Московской области, СанктПетербурге и Ленинградской области, Тверской и Новгородской областях. Базовая станция, работающая в диапазоне 450 МГц, способна покрыть территорию радиусом до 20 км.

По информации ООО "T2 Мобайл" 
26-я Международная выставка технических средств охраны

и оборудования для обеспечения

безопасности и противопожарной защиты

\section{(4) $\underset{\text { Moscow }}{\text { Securika }}$}
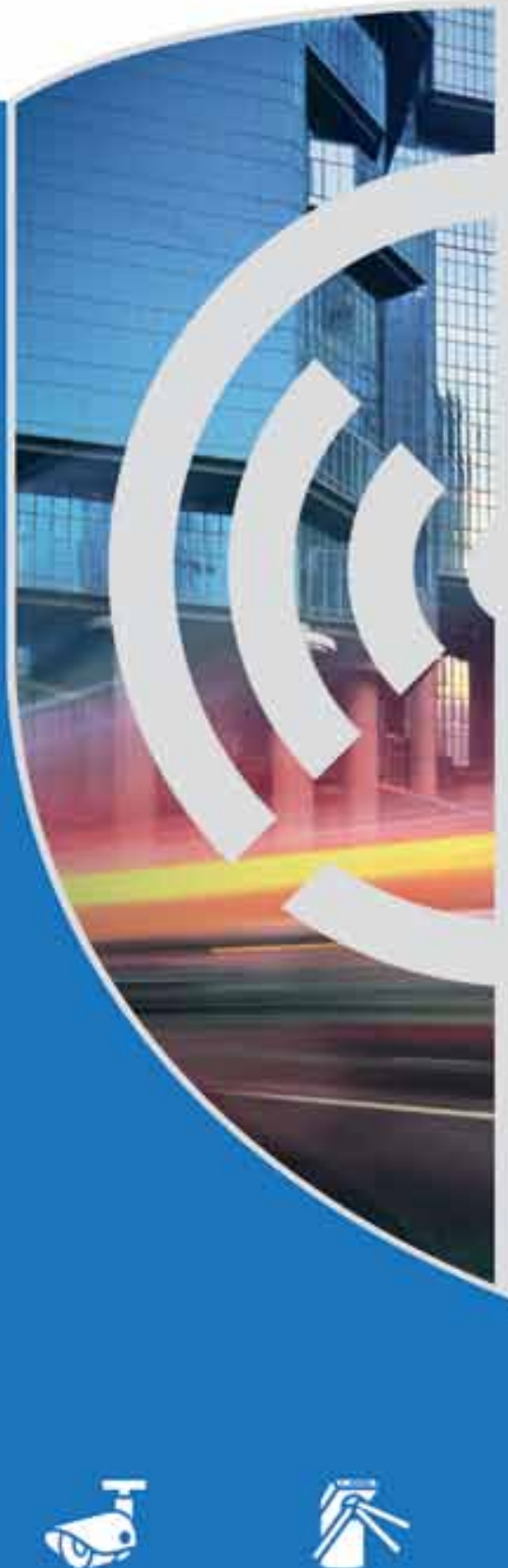

Burterabnoneike

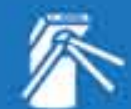

Koripant: Aociyna

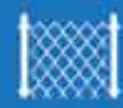

Oxpaita периметра

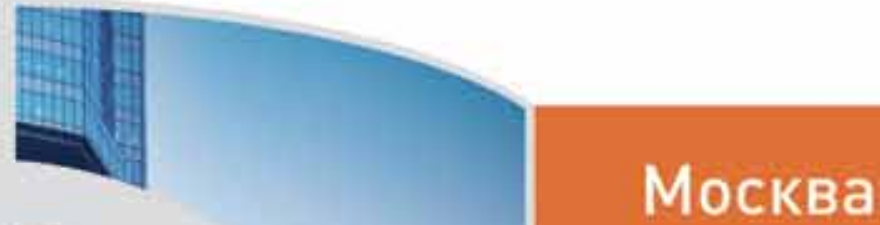

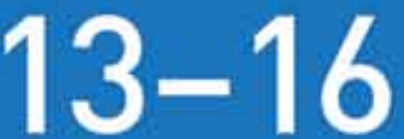

๑ $\square$ ำ

คค

Крокус Экспо

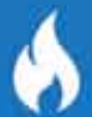

Протинопокарная sach

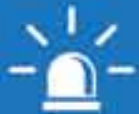

Cirranksaun in onoвецение

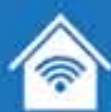

Astomatisauk зданий 